\title{
The electrical and optical behaviour of lamp-annealed Si-implanted InP(Fe)
}

\author{
Govind P Kothiyal† and Kwang S Seoł \\ Solid State Electronic Laboratory, Department of Electrical Engineering and \\ Computer Science, The University of Michigan, Ann Arbor, Michigan 48109, USA
}

Received 13 January 1988, in final form 13 April 1988

\begin{abstract}
The electrical and optical behaviour of halogen-lamp-annealed $\ln \mathrm{P}(\mathrm{Fe})$ implanted with 30 and $70 \mathrm{keV}^{29} \mathrm{Si}^{+}$ions (dose $5 \times 10^{12} \mathrm{~cm}^{-2}$ ) has been investigated. The annealing was carried out in the temperature range $800-850^{\circ} \mathrm{C}$ for a period of 5-20 s using an $\ln \mathrm{P}(\mathrm{Fe})$ proximity cap. The sheet carrier concentration, mobility and low-temperature $(11.5 \mathrm{~K})$ photoluminescence were measured. The results demonstrate that the process of defect removal and reordering in 30-keV-implanted samples is faster than in 70-keV-implanted samples for the same dose. Consequently significantly higher electrical activation of $=84 \%$ and mobility as high as $=3000 \mathrm{~cm}^{2} \mathrm{~V}^{-1} \mathrm{~s}^{-1}$ have been achieved for shallow implantations ( $30 \mathrm{keV}$ ) which are among the best values reported so far with a proximity cap for the InP system. Therefore, an InP proximity cap can be conveniently used without resorting to the complications of dielectric encapsulation, particularly for shallow implantations, for fabrication of InP-based devices.
\end{abstract}

\section{Introduction}

Indium phosphide and its related alloys have stimulated considerable interest in recent years because of their applications in several electronic and opto-electronic devices (Hirota et al 1985, Pande et al 1984, Kim et al 1981, Campbell and Ogawa 1982). Various devices can be fabricated by employing the ion implantation technique for doping. For the activation of the dopants in these materials, transient annealing is gaining importance, as it offers significant advantages over conventional furnace annealing (Masum Choudhury et al 1983, Kuzuhara et al 1984, Armiento and Prince 1986). The electrical and optical behaviour of the implanted and transient annealed InP has been investigated by various workers (Armiento and Prince 1986, Lile et al 1983, Lorenzo et al 1983, Vaidyanathan and Dunlop 1984, Gill and Sealy 1984, Kirrilov et al 1985, Kamiya et al 1986. Rao 1987, Konig et al 1985, Kim et al 1987). However, most of the reported work is concerned with the use of dielectric encapsulation (Armiento and Prince 1986, Lile et al 1983, Lorenzo et al 1983, Vaidyanathan and Dunlop 1984, Gill and Sealy 1984, Kirrilov et al 1985, Kamiya et al 1986, Rao 1987) for maintaining surface integrity and very little work has been reported

\footnotetext{
$\div$ Permanent address: Technical Physics and Prototype Engineering Division, Bhabha Atomic Research Centre, Bombay 400085 , India

I Permanent address: IBM Thomas J Watson Research Center POB 218, Yorktown Height, NY 10598, USA.
}

that involves using proximity capping (Konig et al 1985 , Kim et al 1987). In addition, the studies have in general concentrated on high doses and high implantation energies of various species (Lorenzo et al 1983, Vaidyanathan and Dunlop 1984, Gill and Sealy 1984, Kamiya et al 1986, Rao 1987). Low implantation energies would normally introduce fewer lattice defects/ disorder because there would be a smaller number of collisions of implanted species with lattice atoms and therefore the damage recovery time will be short. The activation temperature during transient annealing would also be lower, as observed by Lile et al (1983) using InP implanted with $50 \mathrm{keV} \mathrm{Si}$ ions. In such cases a proximity cap can be used for minimising the loss of the volatile constituent from the surface during rapid thermal annealing (RTA). Moreover, a proximity cap would produce weaker strain effects on the surface of the implanted layer as compared to dielectric encapsulation, due to the difference between the expansion coefficients (Armiento and Prince 1986, Fehribach et al 1985).

We report here the results of a systematic study of the electrical and optical behaviour of halogen-lampannealed InP(Fe) implanted at room temperature with 30 and $70 \mathrm{keV}^{29} \mathrm{Si}^{+}$ions to a dose of $5 \times 10^{12} \mathrm{~cm}^{-2}$. The projected ranges $\left(R_{\mathrm{p}}\right)$ and standard deviations $\left(\sigma_{\mathrm{p}}\right)$ for 30- and 70-keV-implanted samples are approximately $262 \AA\left(R_{\mathrm{p}}\right)$ and $170 \AA\left(\sigma_{\mathrm{p}}\right)$ and $592 \AA\left(R_{\mathrm{p}}\right)$ and $333 \AA$ $\left(\sigma_{\mathrm{p}}\right)$, respectively. RTA has been performed over the temperature range $800-850^{\circ} \mathrm{C}$ for a period of $5-20 \mathrm{~s}$ 
using polished $\operatorname{In} \mathrm{P}(\mathrm{Fe})$ proximity caps. Electrical activations of about $40 \%$ for $70 \mathrm{keV}$ implantations and $84 \%$ for $30 \mathrm{keV}$ implantations were obtained with a maximum mobility of $3000 \mathrm{~cm}^{2} \mathrm{~V}^{-1} \mathrm{~s}^{-1}$ at room temperature for the $30-\mathrm{keV}$-implanted sample. The latter value of $84 \%$ is significantly higher than values reported so far for proximity capping. The low-temperature PL of rapidly thermally annealed samples is consistent with the electrical measurements.

\section{Experimental details}

Semi-insulating InP crystal wafers of $\langle 100\rangle$ orientation were obtained from Ms Crystal Co., USA. They were implanted with ${ }^{29} \mathrm{Si}^{+}$ions at 30 and $70 \mathrm{keV}$ to a dose of $5 \times 10^{12} \mathrm{~cm}^{-2}$ with the ion beam incident in a nonchannelling direction. Before implantation, 5-10 $\mu \mathrm{m}$ of polished surface was etched using electronic grade $0.5 \%$ bromine-methanol solution to remove the polishing surface damage. The substrates were then thoroughly rinsed with de-ionised water without exposing the surface to air and dried by blowing dry filtered nitrogen over them. The surface morphology was very smooth as seen under an optical microscope. Post-implantation annealing was accomplished in flowing ultra-high-purity Ar in a halogen lamp annealing chamber (Model Heatpulse $210 \mathrm{~T}$, AG Associates). Figure 1 is a schematic representation of the annealing chamber. The samples were placed face down on a bigger polished semi-insulating InP proximity cap as shown in figure 1 . The caps, of sizes at least four times bigger in area than the implanted sample, were specially cleaved from a bigger polished semi-insulating wafer $(0.3 \mathrm{~mm} \mathrm{Th})$. Carefully selected pieces were degreased with electronic grade organic solvents (trichloroethylene, acetone and methanol) and rinsed with de-ionised water. Just before they were used as proximity caps, they were treated in HF for $30-60 \mathrm{~s}$ and rinsed in de-ionised water to remove any oxide, so they are effective in maintaining a phosphorus over-pressure. The annealing temperatures and profiles were measured using a chromel-alumel thermocouple cemented over the four-inch-diameter Si wafer, which acts as a temperature monitor and a support for the samples. The output of the thermocouple is supplied to the feedback loop of the microprocessorbased temperature controller and programmer of the furnace. Different annealing cycles were selected using this microprocessor-based control system. To ensure sharp and reproducible temperature profiles an initial heating for $10 \mathrm{~s}$ at $400^{\circ} \mathrm{C}$ preceded each of the hightemperature annealing stages. The rate of temperature rise is kept constant at $100^{\circ} \mathrm{C} \mathrm{s}^{-1}$. This is an important aspect in the case of RTA as it might have a significant effect on the annealing characteristics (Molnar 1980).

RTA was performed as a function of temperature and time for both types of sample. The annealing temperature was first varied over the range $800-850^{\circ} \mathrm{C}$ with a $5 \mathrm{~s}$ annealing time at each temperature. The annealing

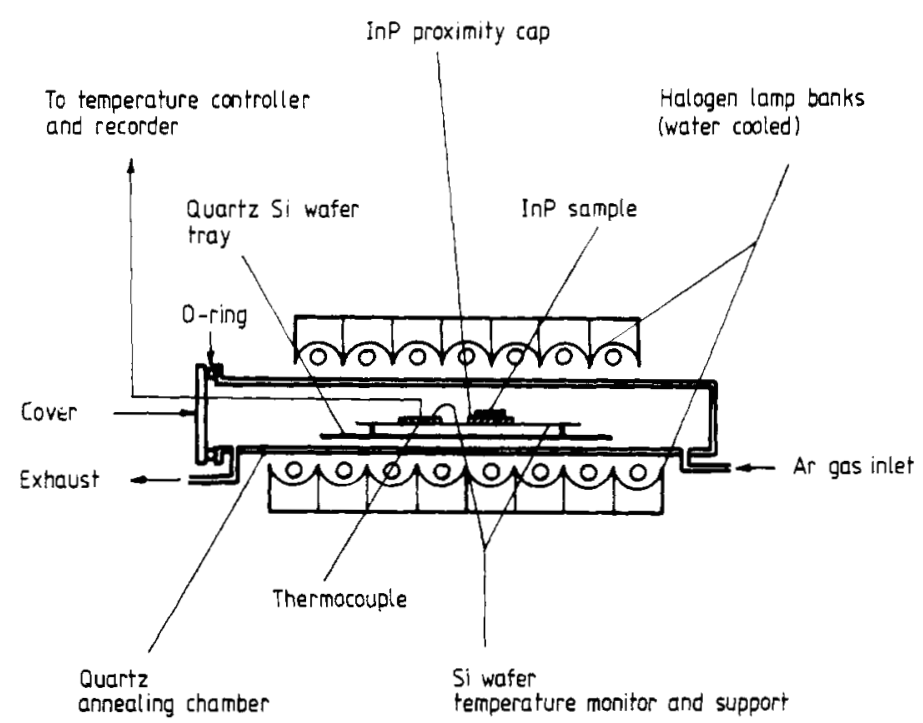

Figure 1. Schematic of the annealing chamber of the rapid thermal annealing system.

time was then varied from 5 to $20 \mathrm{~s}$ at the temperature showing maximum activation.

The sheet carrier concentration and mobility were evaluated from Hall effect measurements using a cloverleaf pattern formed by photolithography. Ohmic contacts were provided with $\mathrm{In}-\mathrm{Sn}$ or evaporated $\mathrm{Ni}-\mathrm{Au}-$ $\mathrm{Ge}-\mathrm{Ni}-\mathrm{Au}$ alloyed at $400-450^{\circ} \mathrm{C}$ for $2 \mathrm{~min}$ in a forminggas ambient.

The low-temperature (11.6 K) PL measurement was performed on annealed samples by mounting them with thermally conductive cryogenic grease on a gold-plated copper cold finger of a closed-cycle liquid-helium cryostat. The luminescence was excited with argon laser radiation (5145 $\AA$ ) and was analysed with a $1 \mathrm{~m}$ JarrellAsh spectrometer in conjunction with a liquid- $\mathrm{N}_{2}$ cooled S-1 photocathode photomultiplier tube. The intensity of the excitation was kept constant $\left(5 \mathrm{~mW} \mathrm{~cm}^{-2}\right)$ for all the samples with the help of calibration provided in the laser instrument and a control sample in the cryostat.

\section{Results and discussion}

With the proper selection and surface treatment of proximity caps we consistenly obtained good surface morphology for the annealed samples. The variation of the sheet carrier concentration (\% activation) and mobility as a function of annealing temperature for 30 and $70 \mathrm{keV}$ samples are shown in figure 2 . It is seen that in both cases the electrical activation initially increases with annealing temperature showing a peak value at $825^{\circ} \mathrm{C}$. At an annealing temperature of $825^{\circ} \mathrm{C}$ the activation obtained for shallow implantation $(30 \mathrm{keV})$ was about $40 \%$ compared with $30 \%$ in the case of $70 \mathrm{keV}$ implantations. The recovery of the damage during annealing would be relatively more for the $30 \mathrm{keV}$ implantation samples as the lattice disorder/damage for $30 \mathrm{keV}$ implantations samples is expected to be less than 


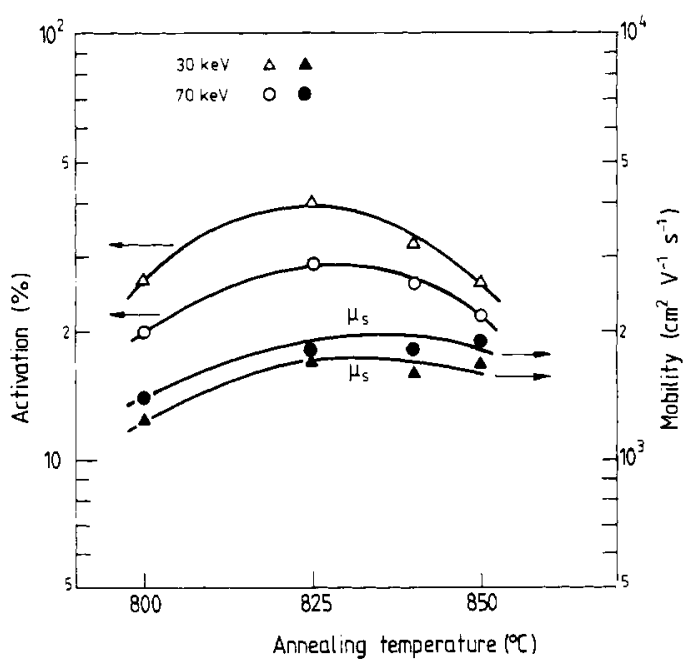

Figure 2. Variation of electrical activation (\%) and Hall mobility as a function of anneal temperature for 30 and $70 \mathrm{keV}^{29} \mathrm{Si}^{+}$implanted $\mathrm{InP}(\mathrm{Fe})$. Annealing time $=5 \mathrm{~s}$.

that of the $70 \mathrm{keV}$ ones. This would of course yield higher activation. The decrease of activation for temperatures above $825^{\circ} \mathrm{C}$ might be due to some loss of $P$ from the surface. Some scattered pits (surface degradation) were seen under the optical microscope for samples annealed at $850^{\circ} \mathrm{C}$.

Figure 3 shows the variation of activation with annealing time at $825^{\circ} \mathrm{C}$ for 30 and $70 \mathrm{keV}$ implantation. We find that sheet carrier concentration (activation) increases with annealing time. The maximum activation for $70 \mathrm{keV}$ implantation was found after $15 \mathrm{~s}$ of annealing while for $30 \mathrm{keV}$ implantations the maximum value was obtained after $10 \mathrm{~s}$ of annealing. For shallow implantations a high activation of $84 \%$ has been obtained. The dependence of mobility of annealing time for both types of sample are also shown in figure 3 . The peak mobility for shallow implantations is higher $\left(3000 \mathrm{~cm}^{2} \mathrm{~V}^{-1} \mathrm{~s}^{-1}\right)$ than that for $70 \mathrm{keV}$ implantations $\left(2600 \mathrm{~cm}^{2} \mathrm{~V}^{-1} \mathrm{~s}^{-1}\right)$. The increase of mobility with annealing time reflects the improvement in crystalline quality of the implanted layer. The mobility in both cases starts decreasing after $10-15 \mathrm{~s}$ of annealing time at $825^{\circ} \mathrm{C}$. It seems plausible that the InP proximity cap does not maintain a phosphorous-rich environment efficiently when the annealing time increases at high temperatures. Consequently the implanted sample may develop some stoichiometry-related surface defects, which obviously reduce carrier mobility in addition to sheet carrier concentration.

Low-temperature PL can be used as a tool to assess the quality of the material. Band-edge luminosity associated with the exciton is extremely sensitive to lattice perfection (Oberstar and Streetman 1982). We have measured $11.6 \mathrm{~K}$ PL for samples implanted with 30 and $70 \mathrm{keV}$ Si after RTA. Typical PL spectra of both types of samples showing $40 \%$ activation are reproduced in figure 4 . The spectra are characterised by strong peaks centred at around 1.417 and $1.378 \mathrm{eV}$. The former peak is normally referred to as the band-edge (BE) emission

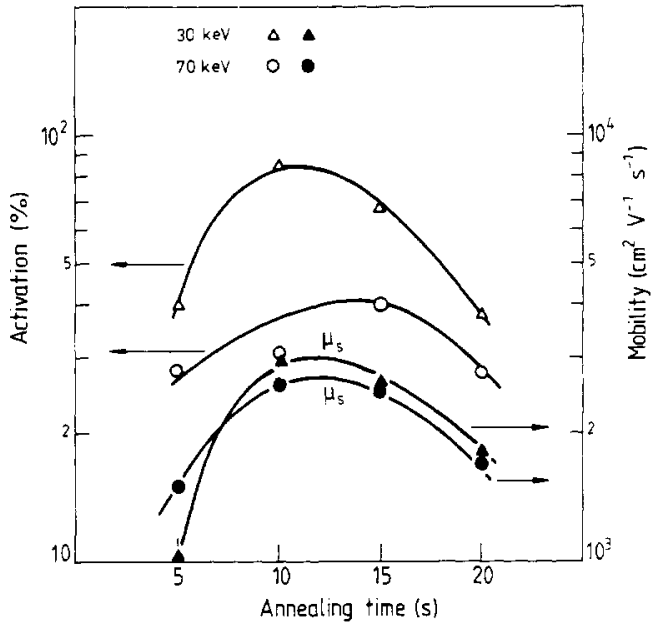

Figure 3. Variation of electrical activation (\%) and Hall mobility with anneal time at annealing temperature $825^{\circ} \mathrm{C}$ for 30 and $70 \mathrm{keV}^{29} \mathrm{Si}^{+}$implanted $\operatorname{lnP}(\mathrm{Fe})$.

and the latter is related to band-acceptor (BA)/donoracceptor (DA) transitions (Kirrilov et al 1985, Molnar 1980). The samples show more or less similar spectra as regards main peaks. The relative intensity of the $\mathrm{BE}$ transition is smaller than the BA/DA peaks in both cases. The PL spectrum for the 70-keV-implanted samples shows an additional feature at around $1.35 \mathrm{eV}$, whereas

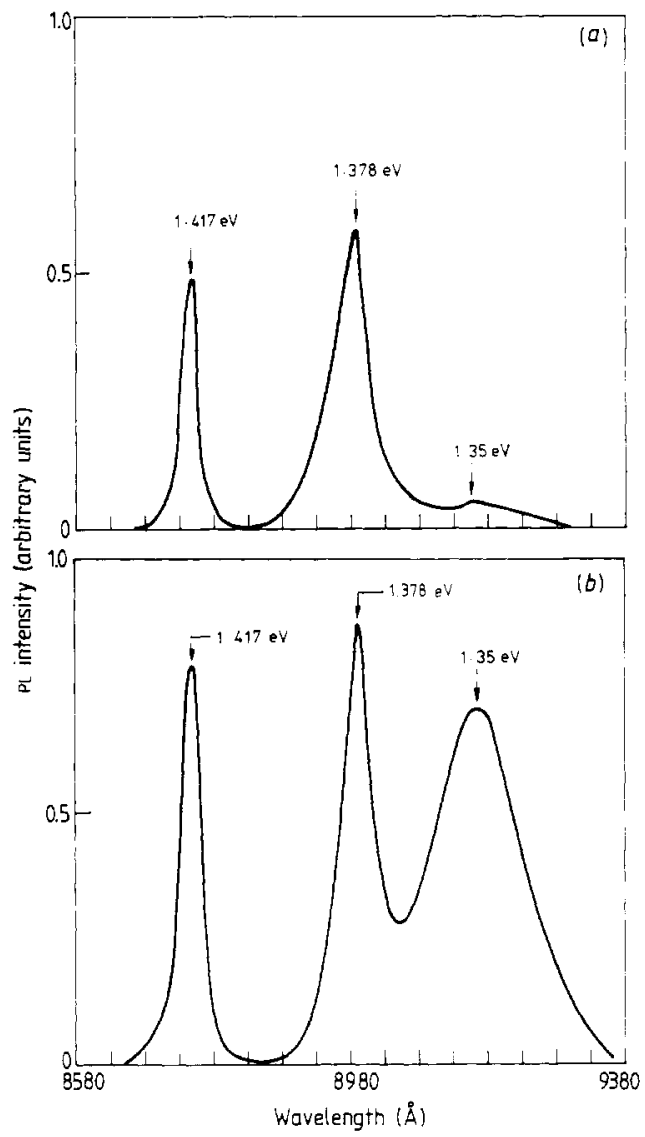

Figure 4. Low temperature (11.5 K) PL spectra of samples showing $40 \%$ electrical activation: (a) $30 \mathrm{keV}$ implant energy and $(b) 70 \mathrm{keV}$ implant energy. 


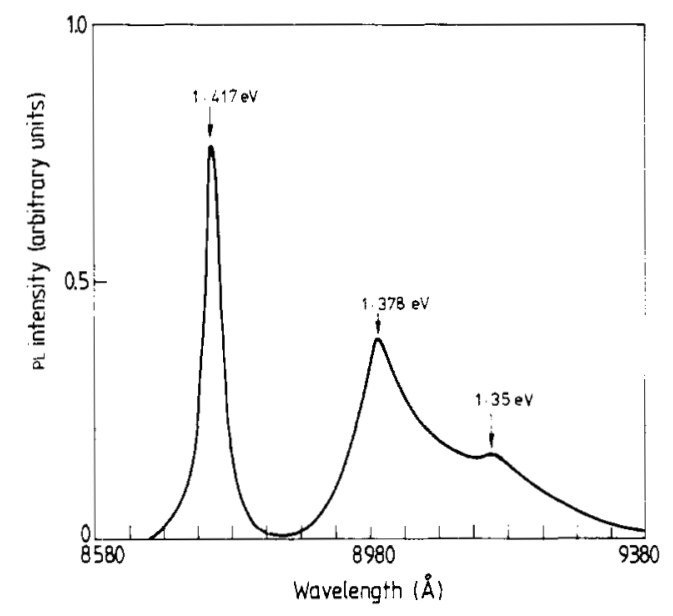

Figure 5. Low-temperature $(11.5 \mathrm{~K}) \mathrm{PL}$ spectrum of $30 \mathrm{keV}$ ${ }^{29} \mathrm{Si}^{+}$implanted $\mathrm{InP}(\mathrm{Fe})$ and annealed at $825^{\circ} \mathrm{C}$ for $10 \mathrm{~s}$ showing electrical activation of $84 \%$.

in the case of the $30 \mathrm{keV}$ implanted sample this peak is considerably smaller. The transition at around $1.35 \mathrm{eV}$ was earlier associated with a complex defect involving Si (Oberstar and Streetman 1982, Bhattacharya et al 1984); however, in recent work Kim et al (1987) have explained this in terms of deep-donor- $(\sim 33 \mathrm{meV})$ acceptor pair transition where the donors are thought to be the native defects or complexes formed as a result of radiation damage. Thus the weaker transition in $30 \mathrm{keV}$ samples observed in the present case is quite consistent with the results of Kim et al (1987). The PL intensity and linewidth of the $\mathrm{BE}$ transition associated with the donor-bound exciton in both cases confirm the recovery of crystallinity after RTA. It may be mentioned that samples implanted without any annealing cycle do not exhibit any features.

The PL spectrum of the $30 \mathrm{keV}$-implanted sample, showing an activation of $84 \%$, is given in figure 5 . It is clear that the relative intensity of the $\mathrm{BE}$ transition has increased as compared with the BA/DA peak centred at around $1.378 \mathrm{eV}$. As higher activation is associated with a higher degree of lattice perfection, the enhancement in relative intensity of the $B E$ peak associated with the bound exciton at around $1.417 \mathrm{eV}$ supports the electrical measurements as regards the improvement in crystal quality.

\section{Conclusions}

The investigations made on $\operatorname{InP}(\mathrm{Fe})$ implanted with $30 \mathrm{keV}$ and $70 \mathrm{keV}{ }^{29} \mathrm{Si}^{+}$demonstrate that the process of defect removal and reordering in $30 \mathrm{keV}$ samples is faster than in $70 \mathrm{keV}$ samples for the same dose $\left(5 \times 10^{12} \mathrm{~cm}^{-2}\right)$. Consequently a significantly higher electrical activation of $84 \%$ and mobility as high as $3000 \mathrm{~cm}^{2} \mathrm{~V}^{-1} \mathrm{~s}^{-1}$ have been achieved for a $30 \mathrm{keV}$ - implanted layer of $\operatorname{In} \mathrm{P}(\mathrm{Fe})$ produced using an InP proximity cap during RTA. The InP proximity cap does not pose any problem during annealing, at least up to $825^{\circ} \mathrm{C}$ and for $10-15 \mathrm{~s}$ anneal time. Under these conditions the surface morphology has been found to be good. Lowtemperature PL characteristics (near-band-edge transitions) obtained in the present work clearly indicate a high degree of lattice damage recovery at $825^{\circ} \mathrm{C}$ during RTA. It can therefore be said that suitably selected InP proximity caps can be conveniently used for maintaining surface integrity of low-energy and low-dose-implanted layers of $\operatorname{In} \mathrm{P}(\mathrm{Fe})$ without resorting to complications of dielectric encapsulation.

\section{Acknowledgments}

The authors acknowledge stimulating discussions with Professor P K Bhattacharya, The University of Michigan, and are grateful for his permission for publication of this work. They would also like to thank Dr B Ghosh for critically reading the manuscript.

\section{References}

Armiento C A and Prince F C 1986 Appl. Phys. Lett. 48 $1623-5$

Bhattacharya P K, Goodman W H and Rao M V $1984 J$. Appl. Phys. 55 509-14

Campbell J C and Ogawa K 1982 J. Appl. Phys. 53 1203-8

Fehribach J D, Ghez R and Oehrlein G S 1985 Appl. Phys. Lett. 46 433-5

Gill S S and Sealy B J 1984 J. Appl. Phys. 56 1189-94

Hirota Y, Okamura M, Hisaki T and Mikami O 1985 Electron. Lett. 21 686-8

Kamiya Y, Shinomura K and Itoh T 1986 J. Electrochem. Soc. $133780-4$

Kim O K, Forrest S R, Bonner W A and Smith R G 1981 Appl. Phys. Lett. 39 402-4

Kim T S, Lestler S D and Streetman B G $1987 \mathrm{~J}$. Appl. Phys. 62 1363-7

Kirrilov D, Merz J L, Kailash R and Shatas S $1985 \mathrm{~J}$. Appl. Phys. 57 531-6

Konig U, Hilgarth J and Tiemann H H $1985 \mathrm{~J}$. Electron. Mater. 14 311-27

Kuzuhara M, Kohzu H and Takayama Y 1984 Mater. Res. Soc. Symp. Proc, 23 651-62

Lile D L, Collins D A and Zeisse C R 1983 IEEE Trans. Electron Devices Lett. EDL-4 231-3

Lorenzo J P, Davies D E, Soda K J, Ryan T G and McNally P J 1983 Mater. Res. Soc. Symp. Proc. 13 683-8

Masum Choudhury A N M, Tabatabaic-Alavi K and Fonstad G 1983 Appl. Phys. Lett. 43 381-3

Molnar B 1980 Appl. Phys. Lett. 36 927-9

Oberstar J D and Streetman B G 1982 J. Appl. Phys. 53 515462

Pande K P, Nair V R K and Aina O 1984 Appl. Phys. Lett. 45 532-4

Rao M V 1987 J. Appl. Phys. 61 337-41

Vaidyanathan K V and Dunlop H L 1984 Mater. Res. Soc. Symp. Proc. 23 687-92 